\title{
Erratum to: Two new species of Myrtaceae (Myrteae) from northern South America
}

Carolyn E. B. Proença ${ }^{1}$, Laura V. S. Jennings ${ }^{2}$, and Eve J. Lucas ${ }^{2}$

${ }^{1}$ Departamento de Botânica, Universidade de Brasília, C.P.4457, Brasília, DF, Cep 70919.970, Brasil

${ }^{2}$ Herbarium, Royal Botanic Gardens, Kew, Richmond, Surrey, TW9 3AE, England, UK

\section{Erratum to: Brittonia}

DOI 10.1007/s12228-010-9125-5

In this article, which was published in Volume 63, Number 1, pp. 46-50, the illustration of Myrcianthes monteucalyptoides Proença \& L. Jenn. (Figure 2) was inadvertently omitted. The figure is shown here. 


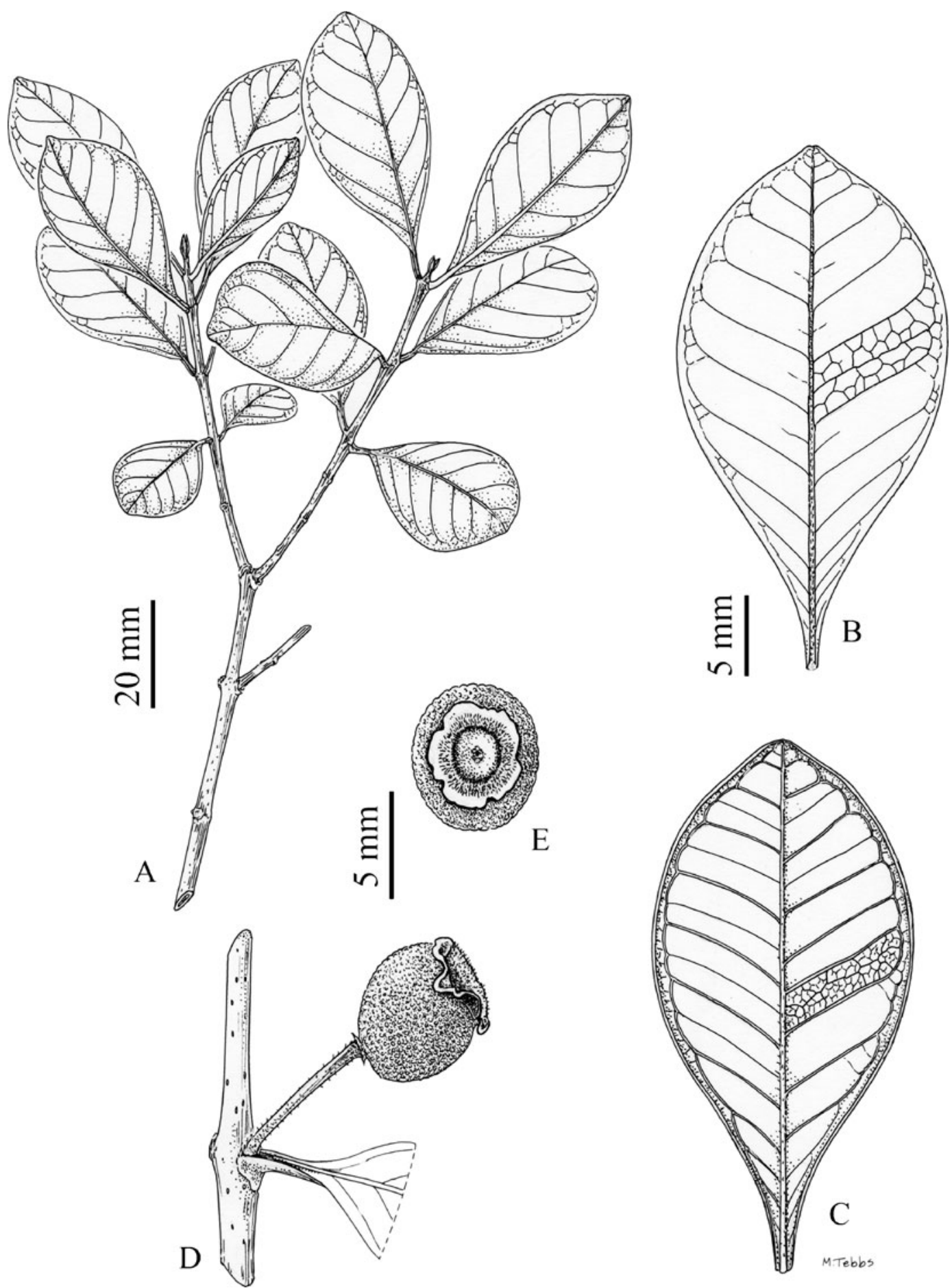

Fig. 2. Myrcianthes monteucalyptoides. A. Leaf-bearing branchlet. B. Abaxial leaf surface with venation detail. C. Adaxial leaf surface with venation detail. D. Fruit, side view. E. Fruit, view from above. (Drawn from the holotype.) 